\title{
UMA BREVE HISTÓRIA DO ENSINO DA ARTE NO BRASIL E SUAS RELAÇÕES COM O NOSSO TEMPO
}

\author{
Charlotte Louise Varella Rodrigues Zimmerman, Carmen Lúcia Dias \\ Universidade do Oeste Paulista - UNOESTE, Programa de Pós Graduação em Educação, Presidente Prudente, SP. E- \\ mail: charlottelouisez@yahoo.com.br
}

\section{RESUMO}

Considerando as orientações pedagógicas do ensino de arte no Brasil atualmente, é de suma importância refletir sobre alguns de seus marcos conceituais: a Missão Artística Francesa no século XIX; a Semana de Arte Moderna de 1922 e a Abordagem Triangular. Este artigo parte de uma pesquisa de mestrado, tem como objetivo descrever os principais pressupostos teóricometodológicos do Ensino de Arte e refletir sobre os desafios e possibilidades do Ensino de Arte na atualidade. A metodologia constou de pesquisa bibliográfica, tendo como aporte teórico epistemológico autores que propõem uma discussão acerca do Ensino da arte no Brasil, das tendências pedagógicas e da importância da arte enquanto conhecimento. Concluímos que o ensino da arte é imprescindível para o desenvolvimento humano de nossos alunos.

Palavras-Chave: Ensino de arte no Brasil. Tendências pedagógicas. Missão Artística Francesa. Semana de arte moderna de 22. Abordagem Triangular.

\section{A BRIEF HISTORY OF ART TEACHING IN BRAZIL AND ITS RELATIONSHIP WITH OUR TIME}

\begin{abstract}
Considering the pedagogical guidelines of art education in Brazil today, it is very important to reflect on some of its conceptual frameworks: the French Artistic Mission in the 19th century; The Modern Art Week of 1922 and the Triangular Approach. This article part of a master's research, aims to describe the main theoretical and methodological assumptions of Art Teaching and to reflect on the challenges and possibilities of Art Teaching in the present time. The methodology consisted of bibliographical research, having as epistemological theoretical contribution authors that propose a discussion about the Teaching of art in Brazil, the pedagogical tendencies and the importance of art as knowledge. We conclude that the teaching of art is essential for the human development of our students.
\end{abstract}

Keywords: Art education in Brazil. Pedagogical trends. French Artistic Mission. Modern art week of 22. Triangular approach. 


\section{INTRODUÇÃO}

Levou-se muito tempo para ocorrer mudanças significativas tanto na história da arte brasileira quanto em seu ensino no nosso país, professores e artistas, em geral, tiveram que preencher uma lacuna de saberes muito extensa após a 'Semana de Arte de 22', porque a mesma lançou os fundamentos do modernismo no Brasil, sendo composta de apresentações de: poesia, música, dança, conferências, concertos, recitais e uma exposição de artes visuais. Sendo todas estas atividades um choque para a sociedade da época; pois os ideais e objetivos da semana eram: a repulsa as concepções passadistas do universo artístico; a independência mental brasileira pelo repúdio aos padrões europeus de arte; a instauração de uma nova técnica de representação da vida; a valorização das culturas indígenas e africanas existentes em nosso país, além de um olhar significativo para a singularidade da natureza tropical. Assim surgindo uma verdadeira renovação das linguagens artísticas na busca e na experimentação, da liberdade criadora e na ruptura com o passado.

Segundo Arslan e lavelberg (2013, p. 2), na escola tradicional predominava a orientação neoclássica, introduzida pela Academia de Belas-Artes instalada pela Missão Francesa (...), mas com o advento da Semana de Arte Moderna de 22 e a repercussão do movimento Modernista no Brasil, a escola renovada incorpora muitos destes valores e inova justamente no ensino da arte, propondo 'o uso de meios e suportes não convencionais nas aulas de arte'. Apenas nos anos de 1980 que haverá uma reorientação no ensino da arte, valorizando não apenas o produto final feito pelos alunos, mas os professores passam a olhar para as etapas necessárias para uma aprendizagem efetiva como: a valorização das ideias, dos processos de criação, seus conceitos e o uso de tecnologias frente a uma sociedade que deseja ser protagonista de sua própria história.

As autoras Derdyk (2010); Barbosa e Coutinho (2009,2011), Bredarioli (2011), enfatizam a importância das relações que devem existir entre os alunos, com seus professores e suas respectivas vidas; nas consequências e na importância do ensino da arte. Ana Mae destaca que

No século XX, o conceito de educação como ensino passa a ser minimizado para dar lugar a ideias socioconstrutivistas, que atribuem ao professor o papel de mediar às relações dos aprendizes com o mundo que devem conquistar pela cognição. A arte tem enorme importância na mediação entre os seres humanos e o mundo. (BARBOSA, 2009, p.13).

O caráter expressivo da arte não caracteriza apenas a sua essência; mas se não o tivesse nem seria arte, pois lhe faltaria o caráter de humanidade acabada. A obra de arte é expressiva enquanto é forma, sendo um organismo que vive por conta própria e contém tudo quanto deve conter. A forma é expressiva enquanto o seu ser é um dizer, conclui-se então que em arte, o conceito de expressão deveria ser o significado daquele que forma.

Perante estas observações, a obra de Bredarioli discorre sobre a necessidade em dominarmos o conhecimento histórico relacionada com a educação através da arte para enfim mudá-la e transformá-la frente à nossa realidade; precisamos discutir as tantas concepções de mundo existentes dentro e fora da escola; que não há como não sofrer influência da sociedade na qual vivemos e nem dos meios de multimídias. Segundo Halbwachs:

A História de Vida e seus correspondentes são usados como metodologia e tema para pesquisas que buscam narrar um outro tipo de história, aquela feita por cada um de nós, pessoas anônimas e comuns. Uma história feita da experiência pessoal, dos pequenos feitos que também constituem uma 'grande' história. Essa tendência tem como intenção conscientizar cada indivíduo de sua importância para a construção - e por isso transformação - de sua própria história individual, a qual, como parte de um conjunto, 
interfere na história coletiva (HALBWACHS apud BREDARIOLI, 2011, p.80 81).

Coutinho analisa as transformações necessárias a serem realizadas dentro da escola e dos caminhos propostos pela Abordagem Triangular que norteia os Parâmetros Curriculares Nacionais ao caracterizar a área do ensino de Arte, pois

Os próprios professores de Arte estão insatisfeitos com os resultados de um ensino exclusivamente focado na livre expressão que não implica uma ampliação de conhecimentos nem atinge a relação do aluno com a sua cultura. A abordagem Triangular [...] vem responder a essas inquietações quando propõe que o currículo escolar articule as dimensões da leitura das produções do campo da arte, sua produção e contextualização. É uma proposta flexível que não envolve uma hierarquia entre as três dimensões, deixando a cargo do educador a construção de seu método de ensino. 0 que irá determinar a articulação e as possíveis relações entre as três dimensões é, em parte, o próprio conteúdo selecionado pelo educador e, essencialmente, suas próprias concepções de educação e de arte. (COUTINHO, 2009, p.173).

Em sua obra, Formas de pensar o desenho, Derdyk nos relata muitas de suas experiências, lembranças e vivências como artista plástica e como arte-educadora, dando a ênfase necessária ao papel primordial que o professor tem na vida de seus alunos. A autora afirma que

É fundamental que o arte-educador reconheça em si a capacidade de exercer $\mathrm{o}$ ato criativo de uma forma tão natural quanto comer, dormir e sonhar. $O$ arte-educador que vive a linguagem gráfica dificilmente incorrerá em erros grosseiros de interpretação e avaliação de um desenho realizado por uma criança. Nesse contexto, as teorias que aí estão para nos auxiliar a conceituar não se tornarão palavras vazias. A vivência fornece o instrumento para o educador tornar-se sensível ao universo gráfico. (DERDYK, 2010, p. 07)

Na verdade a arte revela um sentido às coisas e faz com que um particular fale de modo novo e inesperado, ela é linguagem e faz parte do nosso meio, mostra uma nova maneira de olhar e ver a realidade; e estes são revelados porque são construtivos dentro de um sistema cultural. 0 fazer tem sim um aspecto manual e fabril, arte é produção e também realização em certo sentido, mas não é apenas um momento de execução, de produção, ela é também invenção.

Assim, o objetivo deste estudo foi descrever os principais pressupostos teóricometodológicos do Ensino de Arte e refletir sobre os desafios e possibilidades do Ensino de Arte na atualidade.

\section{METODOLOGIA}

A referente pesquisa bibliográfica (SALVADOR, 1991), parte de uma pesquisa de mestrado, tendo como aporte teórico epistemológico autores que propõem uma discussão acerca do Ensino da arte no Brasil, das tendências pedagógicas e da importância da arte enquanto conhecimento.

\section{DISCUSSÃO}

O ensino tradicional ainda faz parte da maioria das escolas existentes em nossas cidades, independentemente se em escolas estaduais, municipais ou particulares de ensino... Os prédios 
escolares ainda são os mesmos, com muros enormes e grades, pintados muitas vezes das mesmas cores há anos, em suma todas possuem um busto do seu fundador, sempre com algumas bandeiras suspensas em seus mastros, fotos antigas das turmas de alunos extremamente uniformizados, com aquele mobiliário bem gasto de madeira com uma pequena plaquinha com seu número de patrimoniamento, em algumas portas ainda existe a janelinha de vidro para sermos observados dentro da sala de aula, as carteiras e cadeiras de madeira fielmente enfileiradas, o quadro negro e o apagador de giz...

Percebo que não apenas o ensino nos é tradicional, mas tudo que faz referências à escola também. Moran destaca que

Vivemos o paradoxo de manter algo em que já não acreditamos completamente, mas não nos atrevemos a incorporar plenamente novas propostas pedagógicas e gerenciais, mais adequadas à sociedade da informação e do conhecimento, para onde estamos caminhando rapidamente. (2016, p. 16).

Vale a pena ressaltar que a pedagogia tradicional acreditava que o aprendiz era uma tabula rasa, sendo o professor detentor de todo o conhecimento necessário para a vida do aluno e a concepção romântica impregnou as pedagogias progressistas da ideia de que os aprendizes necessitavam apenas de motivação para se "expressarem" e não de instrução. Sobre o assunto, Saviani afirma que

(...) O ensino tradicional propunha-se a transmitir os conhecimentos obtidos pela ciência, portanto, já compendiados, sistematizados e incorporados ao acervo cultural da humanidade. Eis por que esse tipo de ensino, o ensino tradicional, centra-se no professor, nos conteúdos e no aspecto lógico, isto é, centra-se no professor, o adulto, que domina os conteúdos logicamente estruturados, organizados, enquanto os métodos novos se centram no aluno (...) (2012, p.46).

Em relação ao ensino da arte, basta lembrarmo-nos de quando a Pedagogia Tradicional é introduzida no Brasil com a vinda da Missão Artística Francesa em 1816 na Academia Imperial de Belas Artes, esta que era associada à teoria mimética que ditava regras e princípios universais, onde o padrão neoclássico europeu se fundamentava na historiografia da arte vinda desde o Renascimento, pois

(...) na circunstância de primeiro balbucio da temática nacional, já próximo da arrancada republicana, se o tema vinha de nossas terras, o tratamento a ele dado nada tinha a ver conosco, senão no reflexo que era da nossa condição de colonizados. Salvava-se uma ou outra luminosidade tropicalizada na transposição da paisagem ou a caracterização, ocasionalmente genuína, de raros gestos e atitudes. Mas era pouca, migalha. Invertia-se, portanto, o que sucedera com parcela razoável do passado colonial, especialmente no barroco e no rococó. Neste tempo, se o tema, por imposição de exigências religiosas, permanecia distanciado da realidade mais próxima, seu tratamento refletia fundamentos espontaneamente brasileiros. O artista, então, via-se obrigado a copiar item por item, segundo contratos muito claros, os modelos vindos de fora. Mas, quase sempre autodidata ou de formação assistemática, ele projetava na cópia a sua estrutura individual - e por aí 'nacional' - com muito maior intensidade do que viria a fazê-lo o artista do resto do século XIX, 
disciplinadamente escolarizado. (PONTUAL apud FERRAZ; FUSARI, 2010, p. 134).

No campo da educação, durante o período da Arte Moderna, a concepção modernista de ensino da arte rompe com o modelo tradicional, onde o ensino do desenho tinha como objetivos desenvolver o raciocínio e preparar o aluno para o trabalho, tendo sua metodologia o ensino de cópias e memorização, sendo o professor responsável pela transmissão do conteúdo. Na visão 'modernista' seus objetivos passaram a ser o desenvolvimento da criatividade e da expressão do aluno, focando então as necessidades e interesses dos alunos, percebendo que eles tinham características próprias e não pensavam como os adultos.

A arte moderna constituía principalmente uma retomada, em prosseguimento das mais puras linhas de arte de todos os tempos, no que nelas havia de essencial. Nos artistas da 'Semana de arte de 22' são evidentes elementos de formação compositora, destacando-se a influência dos movimentos da Art-Nouveu e assimilações cubistas e expressionistas, estas decididamente incorporadas na obra de Anita Malfati. Mário de Andrade entendeu o movimento 'Modernista' como a fusão de três princípios fundamentais: o direito permanente à pesquisa estética; a atualização da inteligência artística e a estabilização de uma consciência criadora nacional. Sendo a fusão desses três princípios o ato inaugural da modernidade entre nós, mas pensando cronologicamente no pré-modernismo ocorreram dois acontecimentos de grande importância que foram: As exposições de Lasar Segall em 1913 e de Anita Malfati em 1917, que inauguram no país a diferenciação da arte moderna da arte acadêmica, sendo o estopim do modernismo brasileiro. (BREDARIOLI, 2011)

Ao focarmos a parte pedagógica resultante da Semana de Arte Moderna e o pensamento dos modernistas nas décadas de 20 e 30, na qual acontece a substituição do "projeto estético", apenas eles como artistas, por um "projeto ideológico", atuando também como professores, voltamos a pensar nas práticas utilizadas como metodologias de ensino. Acontecendo uma ressignificação em relação à produção artística infantil, pois acreditavam que o verdadeiro artista deveria possuir a espontaneidade que na criança é natural. (BREDARIOLI, 2011)

A criatividade infantil é uma semente que contém em si tudo o que o adulto vai realizar. Interessam-nos as comparações com o mundo infantil para podermos enfocar mais claramente o início dos processos criativos e também o seu desenvolvimento sob determinadas circunstâncias culturais, mas, enquanto fenômeno expressivo, a criação tem implicações diferentes para a criança e para o adulto. Nas crianças, o criar - que está em todo seu viver e agir - é uma tomada de contato com o mundo, em que a criança muda principalmente a si mesma. Ainda que ela afete o ambiente, ela não o faz intencionalmente; pois tudo o que a criança faz, o faz em função da necessidade de seu próprio crescimento, da busca de ela se realizar. (...) (OSTROWER, 2016, p. 130).

Na concepção da arte contemporânea de seu ensino há um compromisso com a nossa cultura e história, pois a mesma tende a abordar múltiplas questões, até mesmo do cotidiano não apenas do artista, mas de toda uma sociedade na qual nossos alunos também fazem parte, estas se somam às técnicas e aos suportes tradicionais ou mesmo a suportes inusitados que podem ser feitos de qualquer matéria com qualquer material, podendo ter como tema 'tudo', pois propõe questionamentos e não mais uma visão pronta do mundo. O trabalho do artista passa a exigir também do espectador uma determinada atenção, um olhar que pensa, que formula leituras tanto de obras quanto de seus conceitos, sem pré-conceitos formados de que isto seja arte e aquilo não, sem querer determinar o que pode e o que não pode ser feito dentro do meio artístico. Percebendo que a arte também é uma forma de pensamento concreto e objetivo, e não 
apenas um meio a se concluir dentro ou fora da sala de aula, mas na sua contextualização, na relevância e experiência reflexiva em cada um de nós ao vermos, analisarmos, interpretarmos, julgarmos e porque não ao produzirmos objetos artísticos. O educador precisa situar-se na cultura do seu tempo, o que significa conhecer a história da arte, entender o momento presente da arte, para fruir a obra de arte. "Decifrados os códigos modernos e pós-modernos, a arte contemporânea pode ser apreciada integralmente". (ROSA; SCALÉA, 2006, p. 52).

Percebemos o quanto o movimento 'Modernista' é entendido como uma cultura contra as normas existentes, desprezando as regras, aproximando a arte com a vida e a cultura de massa. Portanto, a reflexão acerca de suas ações ao longo da história da arte e da educação, implica uma volta ao passado por estas concepções de ensino para refletirmos sobre o que é tradicional, no conteúdo artístico de suas produções, da contemplação, da ausência da participação entre sujeito e objeto, ou da efetiva consumação do gesto criador apenas a partir do olhar do outro...

Nós professores somos os responsáveis em estimular e incentivar nossos alunos a desenvolverem este olhar apurado, para que o mesmo seja significativo, resultando em processos criativos e reflexivos, pois o conceito de arte e suas consequências para a ação educativa têm como objetivo o conhecimento, a fruição e a produção. Na ativação dos conhecimentos prévios dos alunos, para então ampliarmos e efetivarmos um domínio acerca do universo da arte, na qual nossos alunos irão se identificar com determinadas obras e incorporá-las as suas visões de mundo. Diminuindo a mitificação sobre as linguagens da arte, de que apenas quem a faz a entende e da existência do dom, confirmando a capacidade de aprender e compreendê-la como um meio de linguagem possível a todas as pessoas independentemente de seu nível social.

\section{CONCLUSÃO}

Podemos concluir que a atividade artística consiste ainda na atualidade no "formar/expressar", num executar, produzir e reproduzir, realizar, isto que é ao mesmo tempo inventar, figurar, descobrir e redescobrir, viver e reviver... Sabemos que a breve descrição de alguns dados de autores levantados por este artigo indica um caminho a seguir, mas não um caminho qualquer, mas um caminho permeado também por nossas lembranças enquanto professores e alunos. Trazendo reflexões sobre do ensino tradicional à abordagem triangular, das comparações entre as concepções de ensino da arte que ainda norteiam nosso currículo, sendo necessário dominar o conhecimento histórico relacionada com a educação através da arte para enfim muda-la e transforma-la frente à nossa realidade; precisamos ser esclarecidos sobre as tantas concepções de mundo existentes dentro e fora da escola; que não há como não sofrer influência da sociedade na qual vivemos e nem dos meios de multimídias. Podemos ressaltar a importância do nosso papel como professores, desafiando-nos a renovar e atualizar nossos métodos e metodologias de ensino, a fim de propormos situações de atividades sempre desafiadoras aos nossos alunos a partir das linguagens artísticas. Afirmo que esta conscientização é um primeiro passo para não perdermos nosso foco educacional, pois a vivência nos possibilita a ampliação de nossas referências de mundo, em colocar a arte dentro da perspectiva cultural da realidade escolar, valorizando não apenas a nossa bagagem cultural, mas principalmente a dos alunos. Dando ênfase nas diferentes culturas a fim de desenvolvermos uma capacidade de leitura crítica atenta sobre a realidade na qual estamos vivendo.

\section{REFERÊNCIAS}

ARGAN, G. C. Arte Moderna. Tradução de D. Bottman e F. Carotti. São Paulo: Companhia das Letras, 1992.

ARSLAN, L. M. IAVELBERG, R. Ensino de Arte. - 3ạ. Reimpressão da 1ạ. ed. de 2006. São Paulo: Cengage Learning, 2013. - (Coleção ideias em ação/ coordenadora Anna M. P. de Carvalho). 
BARBOSA, A. M. T. (Org.) Arte-educação: leitura no subsolo. 5. ed. São Paulo: Cortez, 2003

BARBOSA, A. M. T. (Org.) Inquietações e mudanças no ensino da arte. 6. ed.- São Paulo: Editora Cortez, 2011.

BARBOSA, A. M. T.; COUTINHO, R. G. Arte/educação como mediação cultural e social. São Paulo: Editora UNESP, 2009.

BARBOSA, A. M. T.; COUTINHO, R.G. Ensino de Arte no Brasil: aspectos históricos e Metodológicos, Rede São Paulo de Formação Docente, 2011.

BRASIL, Parâmetros Curriculares Nacionais. Arte. Brasília: MEC, 1998.

BREDARIOLI, R. L. B. Metodologias para ensino e aprendizagem de arte. Rede São Paulo de Formação Docente, Governo do Estado de São Paulo, 2011.

CANDAU, V. M. F. Diferenças culturais, cotidiano escolar e práticas pedagógicas. Currículo sem Fronteiras, v.11, n.2, p.240-255, jul./dez., 2011.

DERDYK, E. Formas de pensar o desenho: desenvolvimento do grafismo infantil. Porto Alegre: Zouk, 2010.

DUARTE JÚNIOR, J. F. Fundamentos estéticos da educação, 4. ed., Campinas. São Paulo: Papirus, 1995.

DUARTE JÚNIOR, J.F. Por que arte-educação?-8. ed. Campinas, SP: papiros, 1996;(Coleção Ágere).

FERRAZ, M. H. C. T.; FUSARI, M. F. R. Arte na educação escolar. 4. ed. - São Paulo: Cortez, 2010.

GONÇALVES, A. J. Síntese da Modernidade. Guia das Artes, $n^{\circ} 28$, vol.6. Casa editorial paulista. 1992.

LIBANEO, J. C.; OLIVEIRA, J. F.; TOSCHI, M. Educação escolar: políticas, estrutura e organização. 6. ed. São Paulo: Cortez, 2008.

MARTINS, M. C.; PICOSQUE, G.; GUERRA, M. T. T. Teoria e prática do ensino de arte: a língua do mundo - 1. ed. - São Paulo: FTD, 2010. (Coleção teoria e prática)

MORAN, J. M. A educação que desejamos: novos desafios e como chegar lá. 5. ed. Campinas, SP: Papirus, 2012.

MORIN, E. Os sete saberes necessários à educação do futuro. Tradução de Catarina E. F. da Silva e Jeanne Sawaya; revisão téc. de Edgar A. Carvalho. 5. ed. - São PAULO: Cortez; Brasília, DF: UNESCO, 2002.

NÓVOA, A. Profissão professor. Portugal: Porto Editora, 1995

NUNES, B. Introdução à filosofia da arte. São Paulo: Ática, 1999. 
OSTROWER, F. Criatividade e processos de criação. 30. ed. - Petrópolis, Vozes, 2014.

PILLAR, A. D. (Org.) A educação do olhar no ensino das artes. Porto Alegre: Mediação 1999.

SALVADOR, A.D. Métodos e técnicas de pesquisa bibliográfica. Porto Alegre: Sulina Editora, 1991.

SAVIANI, D. Escola e democracia. 41ä. ed. Campinas: Autores Associados, 2009.

SCHRAMM, M. L. K. As Tendências pedagógicas e o ensino-aprendizagem da Arte. In: PILLOTTO, S. S. D.; SCHRAMM,M.L. K. (Org.) Reflexões Sobre o Ensino das Artes. Joinville: Ed. Univille, 2001, v1. 